\title{
Smear positive pulmonary tuberculosis among suspected patients attending metehara sugar factory hospital; eastern Ethiopia
}

\author{
Yohanes A, Abera S, ${ }^{*}$ Ali S \\ Department of Medical Laboratory Sciences and Pathology, Jimma University, Jimma, Ethiopia
}

\begin{abstract}
Background: Tuberculosis is a major public health problem throughout the world. Nearly one third of the world's population is infected with Mycobacterium tuberculosis (MTB) and hence at risk of developing active disease. Tuberculosis is a major cause of morbidity and mortality in Ethiopia, and the country belongs to one of the most affected high burden countries.

Objective: To determine the prevalence of smear positive pulmonary tuberculosis (PTB) and some associated risk factors among suspected patients attending Metehara sugar factory hospital, East Showa, Ethiopia.

Methodology: A cross- sectional study was conducted from March 25 to May 30/2011 on 113 pulmonary tuberculosis suspected participants. Socio demographic and risk factors data were collected by using questionnaire. Sputum samples from tuberculosis suspects were collected, processed by sodium hypochlorite (bleach) centrifugation sedimentation concentration technique, stained by Ziehl-Neelsen staining and examined by Microscopy.

Result: The overall prevalence of smear positive pulmonary tuberculosis was $14.2 \%$. Statistical significant association was observed between age, family size, history of contact with chronic coughers (TB infected patients), smoking habit and alcoholism with pulmonary tuberculosis $(\mathrm{P}<0.05)$.

Conclusion: The prevalence of smear positive pulmonary tuberculosis is high in Metehara sugar factory hospital. The magnitude is higher in the economically productive age group. Smoking, alcoholism and contact history with chronic coughers are highly associated with smear positive pulmonary tuberculosis Therefore, intensification of health education, early case finding \& treatment are recommended to reduce the spread of the disease.
\end{abstract}

Key words: Metehara, Smear positive, Tuberculosis, African Health Sciences 2012; 12(3): 325 - 330 http://dx.doi.org/10.4314/ahs.v12i3.12

\section{Introduction}

Tuberculosis infects one third of the world's population and hence at risk of developing active disease $^{1}$. It still remains to be a major public health problem among the under developed world, because of poverty, HIV pandemic, movement of displaced people and emergency of multidrug-resistant strains ${ }^{1,2}$. Tuberculosis is a bacterial disease caused by Mycobacterium tuberculosis complex which includes most of the time $M$. tuberculosis and occasionally by M. bovis, $M$, africanum and $M$. canetti ${ }^{1}$. These organisms are also known as tubercle bacilli or Acid-fast- bacilli. When examining sputum containing tubercle bacilli processed by Ziehl-Neelsen stain under the microscope, the bacilli stained red. This is because they retain the primary dye even after washing with

\begin{tabular}{|l|}
\hline${ }^{*}$ Correspondence author: \\
Solomon Ali \\
Jimma University \\
College of Public Health and Medical Sciences \\
Department of Medical Laboratory Science and \\
Pathology \\
Tel: +251-0471-120149 \\
E-mail:solomon.ali@ju.edu.et \\
solali2005@gmail.com \\
\hline
\end{tabular}

African Health Sciences Vol 12 No 3 September 2012 acid alcohol due to the waxy component of their cell wall ${ }^{3}$.

According to World Health Organization (WHO) 2011 report, 8.8 million new cases of TB were registered around the world. Majority (35\% and 30\% were reported from south East Asia and Africa respectively). Additionally, 1.1 million deaths were reported, majority was from Asia (59\%) and Africa $(26 \%)^{4}$.

TB is one of the major causes of morbidity and mortality in the horn of Africa with Ethiopia carrying a heavy burden. Ethiopia is the third most populous country in Africa and number seven in the countries with highest TB burden in the world ${ }^{5}$. According to Ethiopian federal Ministry of health $(\mathrm{MOH})$ hospital statistics data, tuberculosis is the leading cause of morbidity, the third cause of hospital admission, and the second cause of death after malaria ${ }^{6}$.Ethiopia reported 141,909 all types of TB cases in 2007; this being one of the largest reported caseloads in the world after China, India, Nigeria and South Africa ${ }^{17}$.According to WHO report of 2011, in Ethiopia the incidence of all forms of TB was $261 / 100,000$ per year and the prevalence of all forms of TB was 394/100,000 population per year ${ }^{4}$. 
The expanded scope of the new strategy for TB control comprises interventions against TB, intensified case finding, cure and TB preventive treatment. Hence, this study determined the prevalence of smear positive pulmonary tuberculosis and some associated risk factors among suspected cases for pulmonary tuberculosis at Metehara sugar factory hospital ${ }^{8}$.

\section{Method}

\section{Study design and setting}

A cross-sectional study was conducted at Metehara sugar factory hospital from March 25 to May 30, 2011. Metehara is located at $200 \mathrm{~km}$ South East of Addis Ababa; the capital of Ethiopia. The total population of Metehara sugar factory is 22,025.

\section{Sampling technique and sample size}

Convenient sampling technique was implemented to include all suspects of PTB who were sent to Metehara sugar factory hospital (MSFH) laboratory within the specified study period. A total of 126 suspected patients were estimated by single population proportion formula by using Prevalence $=10.6 \%$ Gebre and Lucy (2010), 95\% Confidence interval and $5 \%$ margin of error ${ }^{10}$.

\section{Data collection}

All clinically suspected cases of PTB who were sent to the laboratory with a request form for $\mathrm{AFB}$ examination during the data collection period were interviewed for socio demographic and risk factor data by using a well organized questionnaire.

\section{Specimen collection}

Sputum samples were collected from 113 participants by trained laboratory technologist according to the national tuberculosis and leprosy control program (NTLCP) manual standard procedures on the collection of sputum sample for PTB suspect cases (i.e. spot- early morning - spot). Bleach concentration technique was done as described previously ${ }^{3}$. The sediments were placed on new frosted scratch-free glass slides to make a good smear. The smear was allowed to air dry, fixed and stained by Ziehl-Neelsen (Difco,BBL ${ }^{\text {TM }}$,Maryland,USA) staining technique. Then, the preparation was dried and examined microscopically by experienced medical microbiologist. Finally, the result was noted on laboratory data collection format and the patient result was reported accordingly.

\section{Quality Assurance}

For quality assurance instruments and reagents were checked for reliability and reproducibility of the test before any test was started. Patients were instructed on how to produce appropriate sputum specimen. After collection of specimen, it was prepared and tested according to standard operating procedures (SOPs).

\section{Data analysis and interpretation}

Data was processed manually and analyzed by using simple descriptive statistics to test association between positivity rate and independent variables. The presence of risk factor association with pulmonary tuberculosis was tested using chi- square test. In this study p-value $<0.05$ is considered as statistically significant

\section{Ethical consideration}

The study was approved by the department of medical laboratory science and pathology ethical committee. Letter of support was delivered to Metehara sugar factory. The objective of the study was clearly explained for MSFH administrators and other concerned bodies prior to the actual data collection time. Permission to undertake the research was obtained from the hospital officers. Moreover, the purpose of the study was explained for each study subjectbefore data collection and written consent was obtained. Subject with smear positive PTB were linked with DOTS at the hospital for treatment free of charge.

\section{Results}

A total of 113 suspects of pulmonary TB who had cough of more than two weeks of duration were included in this study. The observed age ranges from 12-63 years with mean of 37.4years. Out of these $64 / 113(56.6 \%)$ of the participants were male and $49(43.4 \%)$ of the participants were female.

Acid fast bacilli were detected among sixteen suspects. Accordingly the overall prevalence of smear positive pulmonary tuberculosis was $14.2 \%$. Ten out of sixty four (15.6\%) of male suspects and 6/ $49(12.2 \%)$ of female suspects were diagnosed as smear positive pulmonary tuberculosis. In this study $8 / 29(27.6 \%)$ of age group 30-44years participants were diagnosed as smear positive pulmonary tuberculosis. Significant association was demonstrated between age group 30-44 years and smear positive pulmonary tuberculosis $(\mathrm{p}=0.048)($ table- 1$)$. 
Concerning the ethnicity of the study population, majority $37 / 113(32.7 \%)$ of participants were Oromo. In line with this result there was no significance difference observed regarding smear positive pulmonary tuberculosis among different ethnic groups. $(p=0.992)$ (table-1).

Table 1: Distribution of PTB in relation to socio demography among study population of MSFH, 2011

\begin{tabular}{|c|c|c|c|c|c|}
\hline \multirow[t]{2}{*}{$\overline{\text { Age }}$} & \multicolumn{4}{|c|}{ Sputum examination } & \multirow[b]{2}{*}{ p-value } \\
\hline & Positive $(\%)$ & Negative $(\%)$ & Total & $\%$ & \\
\hline$\leq 14$ & $1(12.5)$ & $7(87.5)$ & 8 & 7.1 & $\mathrm{p}=0.048$ \\
\hline $15-29$ & $4(18.2)$ & 18(81.8) & 22 & 19.5 & \\
\hline $30-44$ & $8(27.6)$ & $21(72.4)$ & 29 & 25.6 & \\
\hline$\geq 45$ & $3(5.6)$ & $51(94.4)$ & 54 & 47.8 & \\
\hline Total & $16(14.2)$ & $97(85.8)$ & 113 & 100 & \\
\hline \multicolumn{6}{|l|}{ Sex } \\
\hline Male & $10(15.6)$ & $54(84.4)$ & 64 & 56.6 & $\mathrm{p}=0.664$ \\
\hline Female & $6(12.2)$ & 43 & 49 & 48.4 & \\
\hline Total & $16(14.2)$ & $97(85.8)$ & 113 & 100 & \\
\hline \multicolumn{6}{|l|}{ Ethnicity } \\
\hline Oromo & $6(16.2)$ & $31(83.8)$ & 37 & 32.7 & $\mathrm{p}=0.992$ \\
\hline Amhara & $2(13.3)$ & $13(86.7)$ & 15 & 13.3 & \\
\hline Kembata & $3(12.5)$ & $21(87.5)$ & 24 & 21.2 & \\
\hline Hadiya & $4(14.3)$ & $24(85.7)$ & 28 & 24.8 & \\
\hline Other & $1(11.1)$ & $8(88.9)$ & 9 & 8.0 & \\
\hline Total & $16(14.2)$ & $97(85.8)$ & 113 & 100 & \\
\hline \multicolumn{6}{|c|}{ Marital status } \\
\hline Single & $3(14.3)$ & $18(85.7)$ & 21 & 18.6 & $\mathrm{p}=0.364$ \\
\hline Married & 11(12.6) & $76(87.4)$ & 87 & 77.0 & \\
\hline Divorced & 1 & 1 & 2 & 1.7 & \\
\hline Widowed & 1 & 2 & 3 & 2.7 & \\
\hline Total & $16(14.2)$ & $978(5.8)$ & 113 & 100 & \\
\hline \multicolumn{6}{|l|}{ Religion } \\
\hline Orthodox & $8(14)$ & $49(86)$ & 57 & 50.4 & $\mathrm{p}=0.81$ \\
\hline Protestant & $5(12.8)$ & $34(87.2)$ & 39 & 34.5 & \\
\hline Muslim & $2(14.3)$ & $12(85.7)$ & 14 & 12.4 & \\
\hline Other & 1 & 2 & 3 & 2.7 & \\
\hline Total & $16(14.2)$ & $97(14.2)$ & 113 & 100 & \\
\hline
\end{tabular}

With regard to the literacy status of the study population, the majority $87 / 113(77 \%)$ were literate. From these literates $5 / 87(19.2 \%)$ of participants were diagnosed as smear positive pulmonary tuberculosis. There was no statistically significant difference observed between literacy status and smear positive pulmonary tuberculosis (table-2).
Out of the total study population, the majority, 36/ $113(31.9 \%)$ had family size between $5-7$. On the other hand $25 \%$ of participants with family size of 5-7 were diagnosed as smear positive pulmonary tuberculosis. Statistically significant association was observed between family size and smear positive pulmonary tuberculosis $(\mathrm{p}=0.04)$ (table-2). 
Table 2: Distribution of PTB in relation to educational status, occupation, and family size among study population of MSFH, 2011

\begin{tabular}{lccrcc}
\hline Educational status & \multicolumn{2}{l}{ Sputum examination } & & p-value \\
\cline { 2 - 5 } & \multicolumn{1}{l}{ Positive (\%) } & Negative (\%) & Total & \% & \\
\hline Illiterate & $5(19.2)$ & $21(80.8)$ & 26 & 23.0 & $\mathrm{p}=0.398$ \\
Literate & $11(12.6)$ & $76(87.4)$ & 87 & 77.0 & \\
Total & $16(14.2)$ & $97(85.8)$ & 113 & 100 & \\
Occupational status & & & & & \\
Government employee & $8(16.3)$ & $41(83.7)$ & 49 & 42.5 & $\mathrm{p}=0.937$ \\
Merchant & $1(12.5)$ & $7(87.5)$ & 8 & 7.1 & \\
House wife & $3(21.4)$ & $11(79.6)$ & 14 & 11.5 & \\
Student & $3(10.3)$ & $26(89.7)$ & 29 & 25.6 & \\
Other & $1(7.6)$ & $12(92.4)$ & 13 & 13.3 & \\
Total & $16(14.2)$ & $97(85.8)$ & 113 & 100 & \\
Family size & & & & & \\
$<4$ & $4(6.2)$ & $61(93.8)$ & 65 & 57.5 & $\mathrm{p}=0.040$ \\
5-7 & $9(25)$ & $27(75)$ & 36 & 31.9 & \\
8-10 & $2(22.2)$ & $7(77.8)$ & 9 & 8.0 & \\
$>10$ & 1 & 2 & 3 & 2.6 & \\
Total & $16(14.2)$ & $97(85.8)$ & 113 & 100 & \\
\hline
\end{tabular}

In relation to contact history, $7 / 17(41 \%)$ of the participants who had contact with chronic coughers (TB infected patients) were diagnosed as smear positive pulmonary tuberculosis. History of contact with chronic coughers (TB infected patients) was significantly associated with smear positive pulmonary tuberculosis $(\mathrm{p}=0.001)$.

Even if only $12 / 113(10.7 \%)$ of the study population were smokers, $4 / 12(33.3 \%)$ of the

smokers were diagnosed as smear positive pulmonary tuberculosis. Statistically significant association was observed between smoking and smear positive pulmonary tuberculosis $(\mathrm{p}=0.004)($ table-3).

It is indicated that $6 / 21(18.6 \%)$ of alcoholisms were diagnosed as smear positive pulmonary tuberculosis. Statistically significant association was seen between alcoholism and smear positive pulmonary tuberculosis $(\mathrm{P}=0.036) \quad($ table-3)

Table 3: Distribution of PTB and risk factors among study population of Metehara sugar factory hospital (MSFH) from March 25 to April 15, 2011

\begin{tabular}{lcllll}
\hline $\begin{array}{l}\text { Contact history with } \\
\text { chronic coughers } \\
\text { (TB infected patients) }\end{array}$ & \multicolumn{3}{c}{ Sputum examination } & \\
\cline { 2 - 5 } & & & & \\
Yes & $7(41.2)$ & $10(58.8)$ & 17 & 15.0 & $\mathrm{p}=0.001$ \\
No & $9(9.4)$ & $87(90.6)$ & 96 & 85.0 & \\
Total & $16(14.2)$ & $97(85.8)$ & 113 & 100 & \\
Past history of PTB+ & & & & & \\
Yes & 1 & 2 & 3 & 2.7 & $\mathrm{p}=0.334$ \\
No & $15(13.6)$ & $95(86.4)$ & 110 & 97.3 & \\
Total & $16(14.2)$ & $97(84)$ & 113 & 100 & \\
Smoking & & & & & \\
Smoker & $4(33.3)$ & $8(66.7)$ & 12 & 10.7 & $\mathrm{p}=0.004$ \\
Non-smoker & $12(11.9)$ & $89(88.1)$ & 101 & 89.3 & \\
Total & $16(14.2)$ & $97(85.8)$ & 113 & 100 & \\
Alcoholism & & & & & \\
Yes & $6(28.6)$ & $15(71.4)$ & 21 & 18.6 & $\mathrm{p}=0.036$ \\
No & $10(10.9$ & $82(89.1)$ & 92 & 81.4 & \\
Total & $16(14.2)$ & $97(85.8)$ & 113 & 100 & \\
\hline
\end{tabular}




\section{Discussion}

Although concentration technique is more sensitive than direct smear, it is inferior as compared to culture. Thus, one of the limitations of this study is associated with failure to use culture for the detection of AFB due to resource constraints. The other limitation is employing non probability sampling technique for selection of study participants. This is done based on the assumption that all suspected patients were homogeneous groups.

In this particular study, the overall prevalence of sputum smear positive pulmonary tuberculosis was $16(14.2 \%)$. As compared to a study done in Addis Ababa health centers, Ethiopia (2011), which reported $21.3 \%$ prevalence, the finding of this study is lower. This might be associated with the health institution intended purpose difference and the community treated ${ }^{11}$. In Ethiopia one of the goals of health centers is early detection and treatment of tuberculosis. Most cases of tuberculosis from the whole community is expected to be detected and treated in health centers.

The finding of this study is higher than a study done in Jimma Seka, Ethiopia (2010), West Gojam Ethiopia (2009) and cape town, South Africa (2006) which reported the prevalence of sputum smear positive as $10.6 \%, 4 \%$ and $8.5 \%$ respectively ${ }^{10,12,13}$. The possible justification for this discrepancy might be associated with the methodology difference; the above mentioned studies screened acid fast bacilli by Ziehl-Neelsen staining technique in direct smear which has low sensitivity as compared to bleach concentrated smears.

The overall prevalence $14.2 \%$ indicated in this study is comparable with study done in Tanzania (2009) which reported the prevalence of AFB as 14 $(12.7 \%)$. In this study patients with less than one week of cough duration were purposefully included. This in turn might have a contribution for slight decrease in overall sensitivity of the diagnosis.

In this study the highest prevalence of sputum smear positive cases were seen between the ages of $30-44$. In this age group $8(27.6 \%)$ of the suspects were smear positive pulmonary tuberculosis patients. Additionally statistical significant association was demonstrated between age and smear positive pulmonary tuberculosis $(\mathrm{p}=0.048)$. In comparison with studies done in Addis Ababa Ethiopia (2011), Gojjam, Ethiopia (2009) and Saharia Madhya Pradesh, India $(2010)(11,12,15)$, the finding of this study is consistent. In the above reports it is indicated that tuberculosis infection rate is high at age range of 25-49 years.

In this study it seems that as the number of family size per house hold increase the prevalence of smear positivity also increases. Family size 5-7 was highly affected by pulmonary tuberculosis. Statistically significant association was observed between smear positive pulmonary tuberculosis and family size. In different reports it was indicated that transmission of pulmonary tuberculosis is increased with poverty, malnutrition and crowded living condition. Different studies indicated individuals living in larger family size members are at higher risk of developing pulmonary tuberculosis ${ }^{16,17}$. On the contrary there is also a report that couldn't demonstrate association between family sizes and smear positive pulmonary tuberculosis ${ }^{18}$

The distribution of pulmonary tuberculosis was also measured in terms of contact history with chronic coughers (TB infected patients), smoking habit and alcoholism to trace the epidemiological features of the disease. In this study, the rate of pulmonary tuberculosis was significantly high in those who had contact with chronic coughers (TB infected patients), drinking of alcohol and in those who are smokers. This finding is consistent with studies done in Jamu district (2002), China (2001), India (2001), Switzerland (2008) and India (2011) ${ }^{18-21}$.

\section{Conclusion}

The prevalence of smear positive PTB in this particular study population was $14.2 \%$ furthermore, results of the present study revealed that history of contact with chronic coughers, family size and smoking and alcoholism were risk factors for pulmonary tuberculosis

\section{Acknowledgments}

We would like to acknowledge Jimma University for providing grant for this study. We are grateful for the department of medical laboratory sciences and pathology for facility support. We would also like to acknowledge Metehara Hospital officials and study participants.

\section{Competing Interest}

We declare that there is no competing interest regarding this research. 


\section{References}

1. Demissie M, Omer OA, Lindjorn B, Hombergh J. Tuberclosis In: Berhane Y, Hailemariam D and Kloos (Eds): The Epidemiology and Ecology of Health and Disease in Ethiopia. Shama Books, Addis Ababa, Ethiopia. 2006: 409-434.

2. Bone A, Aerts A, Grzemska M, et al. Tuberculosis control in prisons: a manual for programme managers. WHO/CDS/TB/ 2000.281. Geneva, Switzerland: World Health Organization, 2000.

3. Chees brough M, Medical laboratory manual for tropical countries, vol. II, 2002: 73;289- 291.

4. WHO report (2011) Global tuberculosis control ISBN 9789241564380 WHO press, World health organization, 20 avenue Appia 1211 Geneva 27 Switzerland. http://www.who.int/tb/ publications/global report/2011/gtbr11 full.pdf

5. Abdi A, Gunnar B, and Fekadu A, pastoralism and delay in diagnosis of TB in Ethiopia. From http;/ / WWW Biomed central.com .East Afr J Public Health. 2009 Oct; 6 (1):156-9.

6. Federal Ministry of Health: Manual of Tuberculosis and Leprosy and TB/HIV Prevention and Control. 4th edition. Addis Ababa, Ethiopia. Ethio Tikur Printing Press; 2008.

7. Guideline for prevention of transmission of TB in health care facilities, congregate and community settings in Ethiopia. Federal MOH. April 2009.

8. WHO Stop TB strategy, Building on or enhancing DOTS to meet the TB related millennium Development goal WHO/HTM/TB/2006.368

9. Federal democratic republic of Ethiopia population census commission, summary and statistical report of the 2007 population and housing cencus. UNFPA.2008

10. Gebre D and Miamo L. Prevalence of smear positive pulmonary tuberculosis among patients attending Seka Health Center, Jimma, Oromia Region, Ethiopia; East Afr J Public Health. 2010;7 (3):268-73.

11. Deribew A, Negussu N, Melaku Z, Deribe K (2011) Investigation Outcomes of Tuberculosis Suspects in the Health Centers of Addis Ababa, Ethiopia. PLoS ONE 6(4): e18614. doi:10.1371/ journal.pone.0018614.

12. Yimer S, Holm-Hansen C, Yimaldu T and Bjune G. Health care seeking among pulmonary tuberculosis suspects and patients in rural Ethiopia: a community-based study, BMC Public Health 2009, 9:454 doi:10.1186/1471-2458-9-454.

13. English R, Bachmann M, Bateman E, Zwarenstein M, Fairall L, Bheekie A, Majara B, Lombard C, Scherpbier R and Ottoman S. Diagnostic accuracy of an integrated respiratory guideline in identifying patients with respiratory symptoms requiring screening for pulmonary tuberculosis: a crosssectional study. BMC Pulmonary Medicine 2006, 6:22 doi:10.1186/1471-2466-6-22.

14. Ngadaya E, Mfinanga G, Wandwalo E and Morkve O. Detection of pulmonary tuberculosis among patients with cough attending outpatient departments in Dar Es Salaam, Tanzania: does duration of cough matter?, BMC Health Services Research 2009, 9:112 doi:10.1186/1472-6963-9112 http://www.biomedcentral.com/1472-6963/ 9/112

15. Selvakumar N, Yadav R, Tlwari B, Rod VG, Gopi PG, Bhat J, Gadge V, Bhondeley MK, and Wares F. pulmonary TB; a public health prolem amongst the saharia, a primitive tribe of madhya pradesh, central India Int J Infect Dis. 2010; 14 (8); 713-6.

16. Malhotra P, Abrol A, Kaur V, Dhar S, Singh A, Kaul S, Raina RK. Prevalence of tuberculosis in Kishtwar Tehsil of Jammu region in Jammu and Kashmir State. I Indian Med Assoc. 1996; 94(9):334-7.

17. Kondo T, Hotta I, Yamanaka K, Sakakibara H, Miyao M, and Yamada S. Family clusters of pulmonary tuberculosis in a sub urban area of Japan. Respiratory Medicine, 1993; 88(3):205-209.

18. Gupta R, Gupta A ,Jamwal,D, and Suri S. A SocioEpidemiological Study of Tuberculosis in a Rural Area.JKscience,2002; 4(3):119-122.

19. Rao V, Gopi P, Bhat J, Yadav R, Selvakumar N, Wares D. Selected risk factors associated with pulmonary tuberculosis among Saharia tribe of Madhya Pradesh central India. European Journal of Public Health,2011;1-3: doi:10.1093/eurpub/ ckr009.

20. Lönnroth K, Williams B, Stadlin S, Jaramillo E and Dye C. Alcohol use as a risk factor for tuberculosis - a systematic review. BMC Public Health 2008, 8:289 doi:10.1186/1471-2458-8289.

21. Kolappan C and Gopi P. Tobacco smoking and pulmonary tuberculosis, Thorax 2002;57:964-966,

22. Dong B, Ge N, Zhou Y. Smoking and alcohol consumption as risk factors of pulmonary tuberculosis in Chengdu: a matched case-control study, Hua Xi Yi Ke Da Xue Xue Bao. 2001;32(1):104-6 